\title{
Removal versus retention of vascular access devices (VADs) suspected of infection in the intensive care unit (ICU): a narrative review of the literature
}

\author{
*India Lye ${ }^{1,2}$; Amanda Corley ${ }^{1,3}$; Claire M Rickard ${ }^{1,3,4}$; Nicole Marsh ${ }^{5,6}$ \\ 'Menzies Health Institute Queensland, Gold Coast Campus, Griffith University, QLD, Australia \\ ${ }^{2}$ The Prince Charles Hospital, Chermside, QLD, Australia \\ ${ }^{3}$ Alliance for Vascular Access Teaching and Research Group, Griffith University, Nathan, QLD, Australia \\ ${ }^{4}$ School of Nursing and Midwifery, Griffith University, QLD, Australia \\ ${ }^{5}$ Griffith University, QLD, Australia \\ ${ }^{6}$ Royal Brisbane and Women's Hospital, Herston, QLD, Australia \\ *Corresponding author \\ India Lye, RN, Grad Cert (Intensive Care Nursing), Adjunct Research Fellow, Menzies Health Institute Queensland, Griffith University, Room 15, \\ Level 3, Clinical Sciences Building, Gold Coast Campus, Griffith University, QLD, Australia \\ Email india.lye@griffith.edu.au
}

Keywords vascular access device, healthcare-associated infection, removal, retention

For referencing Lye I et al. Removal versus retention of vascular access devices (VADs) suspected of infection in the intensive care unit (ICU): a narrative review of the literature. Vascular Access 2019; 5(2):42-48.

Dol https://doi.org/10.33235/va.5.2.42-48

\begin{abstract}
Background Whether to remove or retain vascular access devices (VADs) when they are suspected of infection is an important clinical question with no certain answer. This review aims to explore current literature related to removal versus retention of central venous catheters (CVCS) and intra-arterial lines (IALS) suspected of infection in the adult intensive care population.
\end{abstract}

Methods A narrative review of studies describing management of VADs suspected of infection in the intensive care unit (ICU) was undertaken. After a systematic search, two clinical studies were included in the review. The methodological rigour of these studies was assessed per the Mixed Methods Appraisal Tool (MMAT).

Results The two eligible studies consisted of one randomised control trial and one prospective observational study, including a total of 448 patients. Both studies scored highly on the MMAT, but only pertained to CVCs. No studies relating to other VAD types were identified. No significant differences in outcome were identified between patients whose VADs were removed or retained in the adult ICU cohort, apart from a reduction in number of CVC replacements in patients whose VAD was retained after infection was suspected.

Conclusions There is minimal evidence pertaining to removal versus retention of VADs suspected of infection in the adult ICU patient cohort, and there are limited recommendations specific to suspected infection guiding clinical practice. As a result, VADs may be unnecessarily removed. Further research assessing these important patient outcomes are urgently needed to inform clinical practice.

\section{INTRODUCTION}

In the intensive care unit (ICU) vascular access devices (VADs) are inserted when patients requirevenous or arterial access to facilitate their treatment 1 . These devices, most commonly peripheral intraarterial lines (IALs) and non-tunnelled central venous catheters (CVCs), play a vital, multi-faceted role in modern-day intensive care clinical practice. IALs enable rapid blood sampling and continuous, real-time haemodynamic monitoring ${ }^{2}$ and, as a result, are the most frequently accessed catheters used in the
$\mathrm{ICU}^{3}$. Similarly, CVCs enable central venous pressure monitoring 4 , administration of irritant intravenous medications, fluids, blood products and parental nutrition, as well as blood sampling'. Multiple lumens of CVCs allow concurrent administration of many different types of medications while reducing the impact associated with numerous needle insertions ${ }^{4}$. This is particularly relevant for the ICU patient population in critical condition who may require multiple inotropic agents, sedation and nutrition administered at the same time. 
While essential to contemporary ICU care provision, VAD use carries a significant risk of complications. One of the most serious complications of VAD use is infection. The VAD insertion requires an invasive procedure necessitating a break in skin integrity that can result in localised insertion site infections and increased risk of VAD-associated bloodstream infections (BSIs) ${ }^{4,6}$. Despite both types of infection being classed as preventable complications? VAD-associated infections represent a significant proportion of total hospital-acquired infections ${ }^{5}$.

Vascular access device-associated infections develop due to catheter contamination by microorganisms and biofilm formation on catheter surfaces 5 . While initial catheter contamination can occur through bacterial translocation from the gastrointestinal tract or BSI from another infectious source, this risk in the clinical setting is low ${ }^{8,9}$. The main route of contamination is the patient's skin flora contaminating the insertion site, or from manipulation of the VAD lumens by clinical staff, resulting in localised VAD infection ${ }^{5}$. Inadequate decontamination of the insertion site and lumens can lead to microbial contamination at the insertion site and colonisation along the outer surface of the catheter (extraluminal) or within the inner lumen of the catheter (intraluminal) ${ }^{5,7}$, with microorganisms subsequently entering the bloodstream.

Blood stream infection is a life-threatening hospital-acquired condition ${ }^{10}$ affecting $7 \%$ of all ICU patients within 1 month of admission". Vascular access device-associated BSIs occur at a

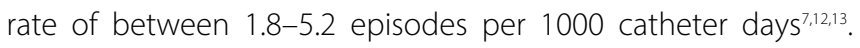
Blood stream infections are a major cause of patient morbidity and mortality ${ }^{14}$ and increase ICU length of stay and healthcareassociated costs ${ }^{10,15}$. To this end, it is estimated that as many as 28,000 ICU patients die of VAD-associated BSIs annually in the United States alone ${ }^{16}$. Importantly, diagnostic criteria for VAD-associated BSIs are very rigorous, which may result in the underestimation of true rates and impact on both patients and healthcare organisations.

How to best manage VADs suspected of infection in the clinical environment is currently unclear. Arguments exist for and against immediate VAD removal on suspicion of infection ${ }^{17}$. On the one hand, VAD-associated BSI has been associated with increased mortality ${ }^{18}$, so delayed catheter removal could lead to worse prognosis if the infection's focus is the catheter itself ${ }^{19}$. On the other hand, immediate removal can also pose problems. Vascular access device-associated infection is often suspected if a patient develops an unexplained fever; however, critically ill patients may develop a fever from sources other than the VAD, not all of which are infection-based ${ }^{17,20}$. Immediate VAD removal on suspicion of infection may necessitate the patient undergoing another VAD insertion ${ }^{21}$, putting the patient at risk of iatrogenic complications such as increased discomfort ${ }^{22}$, pain and distress23, vascular lesions, haematoma, haemothorax, pneumothorax, nerve injury and gas embolism ${ }^{17}$. In addition to patient complications, replacement of a VAD is time-consuming for clinical staff ${ }^{24}$, particularly in patients with difficult vascular access. Such actions negatively impact the efficiency of care delivery and work flow and, if the catheter cannot be replaced promptly, patients experience treatment delays ${ }^{21}$. Removal and re-insertion of VADs also impacts the healthcare organisation financially, with each CVC insertion costing approximately AUD\$375 and each IAL insertion costing AUD\$16125.

A clinical practice guideline specific to managing VADs suspected of infection in the ICU has yet to be developed ${ }^{21}$. Thus clinicians frequently err on the side of caution and opt for early VAD removal as the primary method of source control without waiting for microbiological confirmation of infection ${ }^{21,26,27}$. A large systematic review conducted in 2018 estimates the proportion of CVCs removed for suspected infection, in adult ICU patients, is up to $17 \%$ (20.4 episodes per 1000 catheter days) ${ }^{21}$, yet the same review calculated the incidence of CVC-associated BSI at only 4.59 episodes per 1000 catheter days and local infection at 2.45 episodes per 1000 catheter days ${ }^{21}$. Other literature estimate the proportion of CVCs removed for suspected infection - but finding no evidence of infection upon catheter removal - can be as high as $70-91 \%^{24,28}$. These unacceptably high rates of unnecessary VAD removal demand we generate robust evidence to guide clinicians and determine in what circumstances VAD removal can be safely postponed. This review aims to assess current literature related to removal versus retention of VADs suspected of infection in the adult intensive care population.

\section{METHODS}

This review was based on an electronic literature search and review of published materials from PubMed, Cumulative Index to Nursing and Allied Health Literature (CINAHL) (via EBSCO) and MEDLINE (via EBSCOhost) databases, as well as reference lists of selected identified articles. Medical Subject Headings (MeSH) used were 'catheters' and 'infection', CINAHL Subject Headings used were 'catheters, vascular' and 'infection', while keywords used included 'removal', 'removing', and 'removed', not 'urinary'. Database searches were performed without year restrictions but were limited to those in the English language due to resource limitations. Grey literature was not included in the review. All peer-reviewed journal articles focusing on removal versus retention of VADs suspected of infection in the adult intensive care patient population, regardless of VAD type, were eligible for inclusion in this review. Articles included were critically appraised using the Mixed Methods Appraisal Tool (MMAT)29. Outcomes of interest were VAD removal due to suspected infection, VADrelated infection, and mortality.

\section{RESULTS}

From database searches, 89 titles were identified initially. No further articles were identified in reference lists checks. After 55 duplicate articles were removed, 21 articles were excluded for 
relating to topics not relevant to the research question. Figure 1 shows a diagram of the methodology used. A further 30 articles were excluded because they pertained to paediatric or neonate populations or focused on removal versus retention of VADs after a confirmed VAD-associated BSI diagnosis, or to BSI following catheter removal. Two excluded articles compared VAD-associated infection diagnostic techniques and did not pertain directly to 'watchful waiting' as a method of clinical management of VADs suspected of infection ${ }^{28,30}$. From this, two studies were included in the final review. Characteristics of these studies, involving a total of 448 patients, are detailed in Table 1. Neither study investigated other types of VADs; as such, we cannot comment on the efficacy of removal versus retention in other types of VADs in this review.

Overall, the methodological quality of the included studies was adequate. The randomised controlled trial (RCT) by Rijnders and colleagues ${ }^{24}$ scored $80 \%$ for methodological quality according to the MMAT. Randomisation for this study was completed via a pre-determined computer-generated random sequence in blocks of ten on a 1:1 basis. Allocation of each patient was concealed until time of randomisation, and patient groups were comparable at baseline. Complete outcome data were reported; however, not reported was whether outcome assessors were blinded to the intervention provided at the time of data analysis. The intervention was adhered to with the exception of one patient randomised to the retention group whose CVC was removed before the intervention time period was complete.

The MMAT identified a methodological quality of $90 \%$ for the study by Lorente and colleagues ${ }^{17}$. The participants were representative of the target population, with detailed inclusion and exclusion criteria defined. However, the reasons for eligible patients not being included were not identified in the results. Variables and outcome measures were clearly outlined, with distinct definitions for infection provided. Outcome data appeared complete, and all patients with suspected VADassociated infection were accounted for in the final analysis.

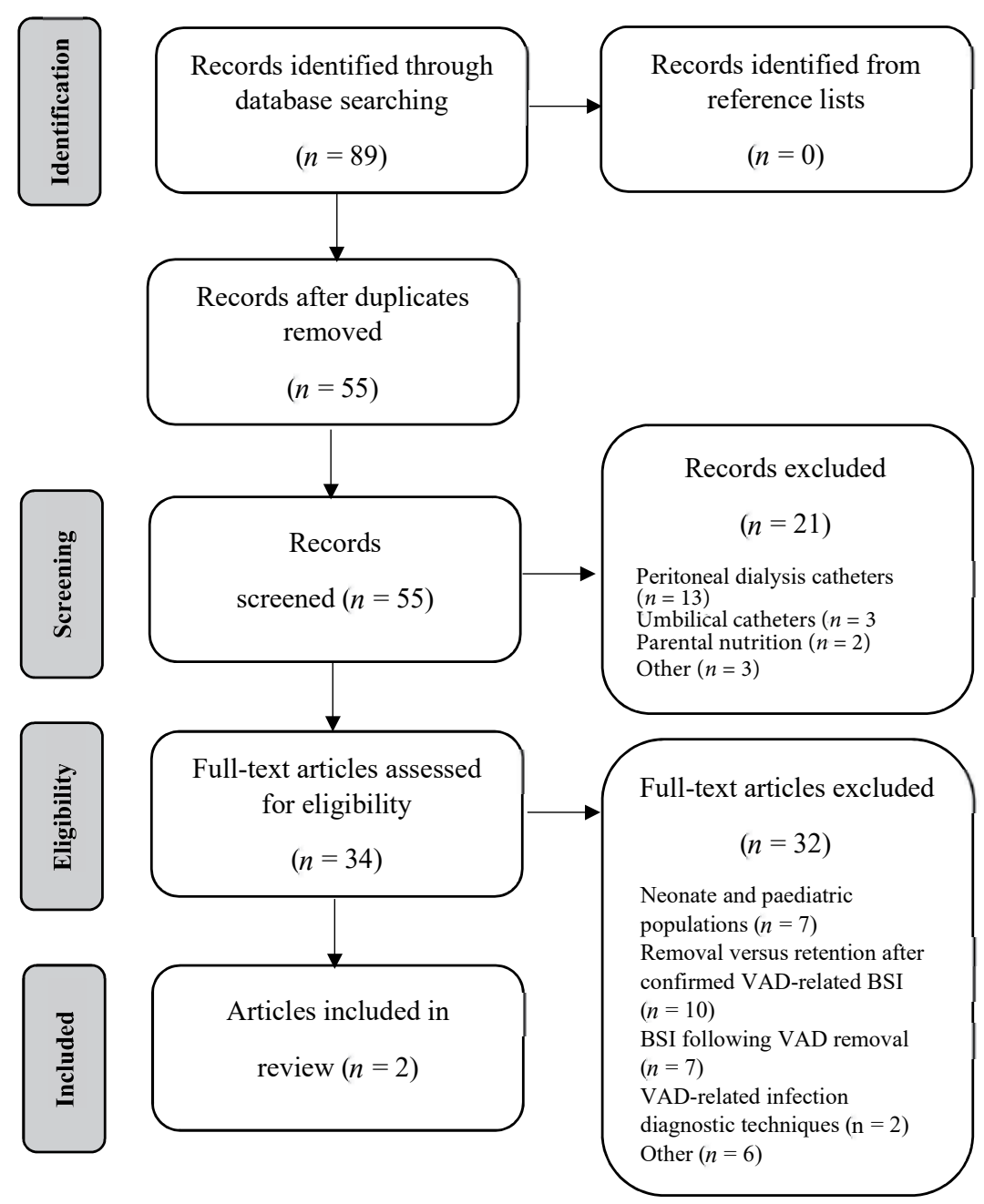

Figure 1: Literature review selection results 
Table 1. Characteristics of included studies.

\begin{tabular}{|c|c|c|c|c|c|c|c|}
\hline Authors & Country & $\begin{array}{l}\text { Type of } \\
\text { ICU }\end{array}$ & Methodology & $\begin{array}{l}\text { Patient } \\
\text { population }\end{array}$ & VAD type & $\begin{array}{l}\text { Outcome } \\
\text { measures }\end{array}$ & Findings \\
\hline $\begin{array}{l}\text { Rijnders et } \\
\text { al. }(2004)^{24}\end{array}$ & Belgium & $\begin{array}{l}\text { Medical } \\
\text { and } \\
\text { surgical }\end{array}$ & $\begin{array}{l}\text { Single centre, RCT. Treatment groups: } \\
\text { Standard of care - catheter removal } \\
\text { on suspicion of infection as per } \\
\text { treating physician } \\
\text { 'Watchful waiting' - catheter only } \\
\text { removed in patients who became } \\
\text { haemodynamically unstable after } \\
\text { study inclusion or developed a } \\
\text { bacteraemia, or after } 5 \text { days of } \\
\text { observation when indicated as per } \\
\text { treating clinician }\end{array}$ & $\begin{array}{l}64 \text { adult } \\
\text { patients }\end{array}$ & $\begin{array}{l}\text { Non-tunnelled } \\
\text { CVCs }\end{array}$ & $\begin{array}{l}\text { CVC changes, } \\
\text { catheter-associated } \\
\text { BSI, hospital length } \\
\text { of stay, temperature, } \\
\text { C-reactive protein, } \\
\text { Sequential Organ } \\
\text { Failure Assessment } \\
\text { (SOFA) score, ICU } \\
\text { mortality }\end{array}$ & $\begin{array}{l}\text { There were less } \\
\text { CVc changes in } \\
\text { the intervention } \\
\text { group }(p<0.01) \text {. } \\
\text { No other } \\
\text { significant } \\
\text { differences found }\end{array}$ \\
\hline $\begin{array}{l}\text { Lorente et al. } \\
(2014)^{17}\end{array}$ & Spain & $\begin{array}{l}\text { Not } \\
\text { reported }\end{array}$ & $\begin{array}{l}\text { Prospective, multicentre, observational } \\
\text { study }\end{array}$ & $\begin{array}{l}384 \text { adult } \\
\text { patients }\end{array}$ & $\begin{array}{l}\text { Non-tunnelled } \\
\text { CVCs }\end{array}$ & $\begin{array}{l}\text { Mortality } 30 \text { days } \\
\text { after suspicion of } \\
\text { CVC-associated } \\
\text { infection }\end{array}$ & $\begin{array}{l}\text { No significant } \\
\text { difference } \\
(p=0.99)\end{array}$ \\
\hline
\end{tabular}

Confounders, particularly ICU admission for association between moment of CVC removal and mortality, were also accounted for. The retention 'intervention' was administered as intended in all patients allocated to that group during the study period.

\section{VAD removal due to suspected infection}

In Rijnders and colleagues' study, 12 of the 32 patients (37\%) assigned to the 'watchful waiting' treatment group had their CVC removed within 10 days of study inclusion, compared to all patients assigned to the standard of care group $(p<0.01)^{24}$. Catheters were removed due to a new BSI diagnosis in four patients for sepsis persisting for 5 or more days after randomisation in five other patients, and for new haemodynamic instability in one further patient. From this it may be inferred that 10 of 32 (31\%) patients assigned to the 'watchful waiting' group had their catheter removed on suspicion of infection.

In contrast, due to study design, infection was suspected in the CVCs of all patients included in the study by Lorente and colleagues. The CVC was removed immediately in 56\% of patients, while $44 \%$ of patients' suspected CVC-associated BSIs were managed with a 'watchful waiting approach ${ }^{17}$. In patients whose catheters were immediately removed, the majority (84\%) required a new CVC to be inserted to continue their treatment. In the 54 patients whose CVCs were managed by 'watchful waiting', catheters were later removed for persistent fever in 45 patients, persistent sepsis in five patients, BSI in three patients, and insertion site suppuration in one patient ${ }^{17}$.

\section{VAD-associated infection}

The observational study by Lorente and colleagues confirmed CVC-associated BSI in 12\% of patients suspected of CVCassociated infection $(n=46)^{17}$. Rijnders and colleagues identified CVC-associated BSI in two patients (6\%) randomised to the standard of care group, and in three patients (9\%) randomised to the 'watchful waiting' group ${ }^{24}$. While organisms responsible for these BSIs were not identified by Rijnders and colleagues, Lorente and colleagues identified the organisms responsible as follows: 19 coagulase negative Staphylococcus spp.; seven Pseudomonas aeruginosa; five Enterococcus faecalis; four Staphylococcus aureus; three Acinetobacter spp.; two Enterococcus faecium; and one each of Klebsiella spp., Streptococcus pyogenes, Streptococcus viridans, Escherichia coli, Enterobacter spp., Serratia marcescens and Candida galbrata ${ }^{17}$.

\section{Mortality}

While the time points at which mortality was measured differed between the two studies, there was no significant difference in mortality between the standard of care and 'watchful waiting' treatment groups in either study. Rijnders and colleagues assessed ICU mortality and identified a rate of $31 \%$ in the standard of care group versus $25 \%$ in the 'watchful waiting' group $(p>0.2)^{24}$. Lorente and colleagues assessed 30-day mortality, but similarly found no differences in immediate versus delayed removal in patients with confirmed CVC-associated BSI $(p=0.99)^{17}$.

\section{DISCUSSION}

This review identified only two studies relevant to the research question, making it impossible to conclusively establish whether removal or retention of VADs suspected of infection positively benefit patient outcomes. None of the current literature assessed patient-important outcomes - for example characteristics or variables that reflect how a patient feels, functions or survives ${ }^{31}-$ other than mortality, such as quality of life and symptom burden. Additionally, there is no evidence surrounding management of other types of VADs suspected of infection. Despite the lack of evidence pertaining to removal versus retention of VADs suspected of infection, there are other resources and diagnostic techniques available that may assist clinicians facing this scenario in their clinical practice. 


\section{Clinical practice guidelines}

Clinicians may refer to published clinical practice guidelines; however, these are limited. Current clinical practice guidelines pertain solely to the management of short-term CVCs, and mainly focus on the managing suspected CVC-associated BSI, not localised CVC-related infection. O'Grady and Chertow ${ }^{32}$ have adapted Infectious Diseases Society of America (IDSA) guidelines into a condensed reference for clinicians, recommending immediate CVC removal in critically ill patients with hypotension and/or organ failure, and in those 'high risk' patients without hypotension or organ failure accompanied by two sets of blood cultures, at least one of which is from a peripheral vein. The Centers for Disease Control and Prevention (CDC) recommend not removing CVCs on the basis of fever alone, but to use clinical judgement regarding the appropriateness of removing the catheter if infection is evidenced elsewhere, or if infection is not suspected as the source of the fever ${ }^{33}$. In addition, guidelines from the IDSA recommend catheter cultures be done when a catheter is removed due to suspected VAD-associated BSI ${ }^{34}$. However, these recommendations do not comment on the management of suspected infection in VAD types other than CVCs or suspected localised VAD infection.

\section{Diagnostic techniques}

Conventional practice to diagnose VAD-associated infection requires $V A D$ removal and culture of the catheter tip paired with blood cultures ${ }^{27}$. Conservative diagnostic techniques for example those not requiring catheter removal ${ }^{30}$ - may aid clinicians in diagnosing VAD-associated infections without risking premature and unnecessary VAD removal. These techniques, particularly differential time to positivity (DTP), have shown good sensitivity and specificity ${ }^{26,35}$ in both longand short-term catheters ${ }^{30,35}$. Studies also demonstrate good clinical utility of concurrent DTP and semi-quantitative superficial cultures of insertion site skin and catheter hub for both VADassociated BSI and catheter tip colonisation in VADs of critically ill patients $s^{27,36}$. Furthermore, a retrospective study spanning 9 years demonstrated no difference in in-hospital mortality between conservative VAD-associated infection diagnostic methods and conventional methods involving removal of the VAD ${ }^{28}$. Details of such conservative diagnostic methods are outlined in Table 2.

Evidence currently recommends combining semi-quantitative superficial cultures and peripheral vein cultures to screen for VAD-associated BSI, and leaving differential quantitative blood cultures as a confirmatory technique $\mathrm{e}^{30}$. However, it was argued that conservative diagnostic techniques may be of limited benefit when trying to avoid unnecessary $V A D$ removal as most catheters are removed early in clinical practice due to unexplained signs of sepsis and not for laboratory-confirmed bacteraemia ${ }^{24}$. Likewise, conservative techniques are not yet readily adopted into routine clinical practice. The reason for this

Table 2. Conservative diagnostic techniques.

\begin{tabular}{|c|c|c|}
\hline Technique & Description & Positivity criteria \\
\hline $\begin{array}{l}\text { Qualitative blood culture through the } \\
\text { VAD }\end{array}$ & $\begin{array}{l}\text { One or more conventional blood cultures are } \\
\text { drawn through the VAD. }\end{array}$ & Any growth. \\
\hline $\begin{array}{l}\text { Quantitative blood culture through the } \\
\text { VAD }^{37}\end{array}$ & $\begin{array}{l}\text { A blood culture is drawn through the VAD } \\
\text { and processed by pour plate methods or lysis- } \\
\text { centrifugation technique. }\end{array}$ & $\geq 100 \mathrm{CFU} / \mathrm{mL}$ \\
\hline Paired quantitative blood cultures ${ }^{37}$ & $\begin{array}{l}\text { Concomitant quantitative blood cultures are drawn } \\
\text { both peripherally and through the VAD. }\end{array}$ & $\begin{array}{l}\text { Cultures are positive from both sites and } \\
\text { the concentrations of microorganisms } \\
\text { in the VAD culture are } 3-5 \text { times greater } \\
\text { than in the peripheral blood culture. }\end{array}$ \\
\hline Differential time to positivity (DTP) $)^{37}$ & $\begin{array}{l}\text { Concomitant conventional blood cultures are } \\
\text { drawn both peripherally and through the VAD and } \\
\text { monitored continuously. }\end{array}$ & $\begin{array}{l}\text { Both blood cultures are positive and } \\
\text { the VAD-drawn blood culture becomes } \\
\text { positive } \geq 2 \text { hours before the peripheral } \\
\text { blood culture. }\end{array}$ \\
\hline Acidrine orange leukocyte cytospin ${ }^{37}$ & $\begin{array}{l}\text { Approximately } 1 \mathrm{~mL} \text { of blood is drawn from the } \\
\text { VAD; the cells are lysed with sterile water and } \\
\text { the specimen centrifuged, stained with acidrine } \\
\text { orange, and examined microscopically. }\end{array}$ & Visualisation of any microorganisms. \\
\hline $\begin{array}{l}\text { Paired DTP and semi-quantitative } \\
\text { superficial cultures }{ }^{27}\end{array}$ & $\begin{array}{l}\text { Concomitant conventional blood cultures are } \\
\text { drawn both peripherally and through the VAD } \\
\text { and monitored continuously, plus swabs of either } \\
\text { the VAD insertion site skin or the catheter hub are } \\
\text { taken. }\end{array}$ & $\begin{array}{l}\text { Both blood cultures are positive, and } \\
\text { the VAD-drawn blood culture becomes } \\
\text { positive } \geq 2 \text { hours before the peripheral } \\
\text { blood culture AND the VAD hub or } \\
\text { catheter insertion site skin swab } \geq 15 \text { CFU. }\end{array}$ \\
\hline Paired VAD lumen blood cultures ${ }^{34}$ & $\begin{array}{l}\text { Concomitant blood cultures are drawn from } \\
\text { different lumens of a VAD. }\end{array}$ & $\begin{array}{l}\text { The CFU are at least three-fold greater in } \\
\text { one lumen blood culture than the other. }\end{array}$ \\
\hline
\end{tabular}

CFU = colony forming units 
is unclear but may be due to relative complexity and $\operatorname{cost}^{28,38}$. Additionally, current clinical guidelines and hospital policies do not advocate specifically for conservative diagnostic methods, instead opting to recommend conventional catheter tip culture for a definitive VAD-associated BSI diagnosis.

\section{Similar literature}

In lieu of definitive evidence and clinical practice guidelines on the management of VADs suspected of infection, clinicians may turn to literature focusing on slightly different aspects of VAD removal versus retention for guidance. A number of studies investigate the removal or retention of VADs after primary VADassociated BSI and secondary bacteraemias are confirmed. Some studies aim to determine whether VADs that cause BSI must be removed as soon as the diagnosis is confirmed, or whether they may be left in situ while the infection is neutralised by other means such as systemic anti-microbial agents and/ or antibiotic hub locks ${ }^{6,8}$. Other studies focus on whether VADs must be removed to ensure they do not become colonised with microorganisms from the bloodstream ${ }^{8}$, and therefore harbour microorganisms after the BSI resolves, increasing the chance of bacteraemia re-occurrence ${ }^{39}$.

The results of the aforementioned studies relating to VAD removal or retention after BSI confirmation are unclear. Some studies conclude that retention of VADs after infection is confirmed increases mortality ${ }^{40-44}$, while others conclude no significant difference between removal or retention in overall mortality $42,45-50$. Additionally, the patient cohorts and outcome measures in these studies vary significantly, with no adult intensive care cohorts reported on. As such, this data may be of limited use in informing clinical practice, but highlights the deficiency of evidence surrounding the topic of removal versus retention of VADs suspected of infection in the adult ICU.

\section{Limitations of this review}

This review has several limitations. Grey literature was not included in this review which may have introduced some publication bias. Limiting the search results to only those in English may have also introduced selection bias into this review. Finally, only one researcher assessed the data which may have created additional reporting bias.

\section{Implications for future research}

This review has identified a significant knowledge gap in the literature. While there are many studies pertaining to removal versus retention of VADs in circumstances where BSI is already confirmed, there is a paucity of evidence relating to clinical circumstances where VAD-associated BSI is suspected. This is particularly true for suspected IAL-associated BSIs, as no literature identified in this review was able to address this important aspect of the research question. There is therefore an urgent need for adequately powered RCTs assessing patient-important outcomes, such as incidence of VAD-associated BSI and mortality, to provide definitive evidence on this important topic.

\section{Implications for clinical practice}

The evidence base regarding clinical management of VADs suspected of infection in the ICU does little to guide clinicians in their decision-making around removal or retention of such VADs. The lack of robust evidence results in well-meaning clinicians removing VADs often not warranting removal, and potentially exposing patients to increased risk of complications, pain and distress. Further, RCTs on the topic of removal versus retention of VADs suspected of infection will generate robust evidence to inform the development of evidence-based clinical practice guidelines. This will aid clinicians' decision-making and reduce the incidence of unnecessary VAD removal in this vulnerable patient population.

\section{CONCLUSIONS}

The literature pertaining to removal versus retention of inspection suspect VADs in the adult intensive care cohort, while limited in quantity, is methodologically rigorous according to the MMAT. However, there is a paucity of evidence in this area, and subsequently there are no clinical practice guidelines for clinicians to refer to when managing patients with VADs suspected of infection. High quality, adequately powered RCTs assessing patient-important outcomes are therefore urgently needed to inform clinical practice.

\section{REFERENCES}

1. Gavin NC, Webster J, Chan RJ, Rickard CM. Frequency of dressing changes for central venous access devices on catheter-related infections. Cochrane Database Syst Rev 2016;2:CD009213.

2. Edwards M, Rickard CM, Rapchuk I, Corley A, Marsh N, Spooner AJ, et al. A pilot trial of bordered polyurethane dressings, tissue adhesive and sutureless devices compared with standard polyurethane dressings for securing short-term arterial catheters. Crit Care Resusc 2014;16(3):17583.

3. Maki DG, Kluger DM, Crnich CJ. The risk of bloodstream infection in adults with different intravascular devices: a systematic review of 200 published prospective studies. Mayo Clin Proc 2006;81(9):1159-71.

4. Ullman AJ, Cooke ML, Mitchell M, Lin F, New K, Long DA, et al. Dressings and securement devices for central venous catheters (CVC). Cochrane Database Syst Rev 2015(9):CD010367.

5. Beloin C, Fernandez-Hidalgo N, Lebeaux D. Understanding biofilm formation in intravascular device-related infections. Intensive Care Med 2017:43(3):443-6.

6. Han Z, Liang SY, Marschall J. Current strategies for the prevention and management of central line-associated bloodstream infections. Infect Drug Resist 2010;3:147-63.

7. Pronovost P, Needham D, Berenholtz S, Sinopoli D, Chu H, Cosgrove S, et al. An intervention to decrease catheter-related bloodstream infections in the ICU. N Engl J Med 2006;355(26):2725-32.

8. Chaftari AM, Hachem R, Raad S, Jiang Y, Natividad E, Chaftari P, et al. Unnecessary removal of central venous catheters in cancer patients with bloodstream infections. Infect Control Hosp Epidemiol 2018;39(2):222-5.

9. Anaissie E, Samonis G, Kontoyiannis D, Costerton J, Sabharwal U, Bodey $\mathrm{G}$, et al. Role of catheter colonization and infrequent hematogenous seeding in catheter-related infections. Eur J Clin Microbiol Infect Dis 1995;14(2):134-7. 
10. Bassetti M, Righi E, Carnelutti A. Bloodstream infections in the intensive care unit. Virulence 2016;7(3):267-79.

11. Garrouste-Orgeas M, Timsit JF, Tafflet M, Misset B, Zahar JR, Soufir L, et al. Excess risk of death from intensive care unit-acquired nosocomial bloodstream infections: a reappraisal. Clin Infect Dis 2006;42(8):1118-26.

12. O'Grady NP, Alexander M, Dellinger EP, Gerberding JL, Heard SO, Maki DG, et al. Guidelines for the prevention of intravascular catheter-related infections. Centers for Disease Control and Prevention. MMWR Recomm Rep 2002;51(RR-10):1-29.

13. National Nosocomial Infections Surveillance. National nosocomial infections surveillance (NNIS) system report: data summary from January 1992 through June 2004, issued October 2004. Am J Infect Control 2004;32(8):470-85.

14. Wisplinghoff $H$, Bischoff $T$, Tallent $S M$, Seifert $H$, Wenzel RP, Edmond MB. Nosocomial bloodstream infections in US hospitals: analysis of 24,179 cases from a prospective nationwide surveillance study. Clin Infect Dis 2004;39(3):309-17.

15. Vincent JL, Rello J, Marshall J, Silva E, Anzueto A, Martin CD, et al. International study of the prevalence and outcomes of infection in intensive care units. JAMA 2009;302(21):2323-9.

16. Berenholtz SM, Pronovost PJ, Lipsett PA, Hobson D, Earsing K, Farley JE, et al. Eliminating catheter-related bloodstream infections in the intensive care unit. Crit Care Med 2004;32(10):2014-20.

17. Lorente L, Martin MM, Vidal P, Rebollo S, Ostabal MI, Sole-Violan J, et al. Should central venous catheter be systematically removed in patients with suspected catheter related infection? Crit Care 2014;18(5):564.

18. Lambert ML, Suetens C, Savey A, Palomar M, Hiesmayr M, Morales I, et al. Clinical outcomes of health-care-associated infections and antimicrobial resistance in patients admitted to European intensive-care units: a cohort study. Lancet Infect Dis 2011;11(1):30-8.

19. Jensen AG, Wachmann CH, Espersen F, Scheibel J, Skinhoj P, FrimodtMoller N. Treatment and outcome of Staphylococcus aureus bacteremia: a prospective study of 278 cases. Arch Intern Med 2002;162(1):25-32.

20. O'Grady NP, Barie PS, Bartlett JG, BleckT, Carroll K, Kalil AC, et al. Guidelines for evaluation of new fever in critically ill adult patients: 2008 update from the American College of Critical Care Medicine and the Infectious Diseases Society of America. Crit Care Med 2008;36(4):1330-49.

21. Takashima M, Schults J, Mihala G, Corley A, Ullman A. Complication and failures of central vascular access device in adult critical care settings. Crit Care Med 2018;46(12):1998-2009.

22. Deshpande $P$, Jain A, Shah PS. Outcomes associated with early removal versus retention of peripherally inserted central catheters after diagnosis of catheter-associated infections in neonates. J Matern Fetal Neonatal Med 2016;29(24):4082-7.

23. Chaftari AM, Raad S, Hachem R, Shah P, Y. J, Nativdad E, et al. Unecessary removal of central venous catheters in patients with bloodstream infections: impact on symptom burden. OFID 2017;4((Suppl 1)):S635.

24. Rijnders BJ, Peetermans WE, Verwaest C, Wilmer A, Van Wijngaerden E. Watchful waiting versus immediate catheter removal in ICU patients with suspected catheter-related infection: a randomized trial. Intensive Care Med 2004;30(6):1073-80.

25. Tuffaha HW, Marsh N, Byrnes J, Gavin N, Webster J, Cooke M, et al. Cost of vascular access devices in public hospitals in Queensland. Aust Health Rev 2018.

26. Evans O, Gowardman J, Rabbolini D, McGrail M, Rickard CM. In situ diagnostic methods for catheter related bloodstream infection in burns patients: a pilot study. Burns 2016;42(2):434-40.

27. Gowardman JR, Jeffries $P$, Lassig-Smith $M$, Stuart J, Jarrett $P$, Deans $R$, et al. A comparative assessment of two conservative methods for the diagnosis of catheter-related infection in critically ill patients. Intensive Care Med 2013;39(1):109-16.

28. Deliberato RO, Marra AR, Correa TD, Martino MD, Correa L, Dos Santos OF, et al. Catheter related bloodstream infection (CR-BSI) in ICU patients: making the decision to remove or not to remove the central venous catheter. PLoS One 2012;7(3):e32687.

29. Hong QN, Pluye P, Fabregues S, Bartlett G, Boardman F, Cargo M, et al. Mixed Methdods Appraisal Tool (MMAT) 2018. Available from: http://mixedmethodsappraisaltoolpublic.pbworks.com/w/file/ fetch/127425851/MMAT_2018_criteria-manual_2018-04-04.pdf

30. Bouza E, Alvarado N, Alcala L, Perez MJ, Rincon C, Munoz P. A randomized and prospective study of 3 procedures for the diagnosis of catheter- related bloodstream infection without catheter withdrawal. Clin Infect Dis 2007:44(6):820-6.

31. Gaudry S, Messika J, Ricard JD, Guillo S, Pasquet B, Dubief E, et al. Patientimportant outcomes in randomized controlled trials in critically ill patients: a systematic review. Ann Intensive Care 2017;7(1):28.

32. O'Grady NP, Chertow DS. Managing bloodstream infections in patients who have short-term central venous catheters. Cleve Clin J Med 2011;78(1):10-7.

33. O'Grady NP, Alexander M, Burns LA, Dellinger EP, Garland J, Heard SO, et al. Guidelines for the prevention of intravascular catheter-related infections. Clin Infect Dis 2011;52(9):e162-93.

34. Mermel LA, Allon M, Bouza E, Craven DE, Flynn P, O'Grady NP, et al. Clinical practice guidelines for the diagnosis and management of intravascular catheter-related infection: 2009 Update by the Infectious Diseases Society of America. Clin Infect Dis 2009;49(1):1-45.

35. Blot F, Nitenberg G, Chachaty E, Raynard B, Germann N, Antoun S, et al. Diagnosis of catheter-related bacteraemia: a prospective comparison of the time to positivity of hub-blood versus peripheral-blood cultures. Lancet 1999;354(9184):1071-7.

36. Kumar A, Sharma RM, Jaideep CN, Hazra N. Diagnosis of centra venous catheter-related bloodstream infection without catheter removal: a prospective observational study. Med J Armed Forces India 2014;70(1):17-21.

37. Safdar N, Fine JP, Maki DG. Meta-analysis: methods for diagnosing intravascular device-related bloodstream infection. Ann Intern Med 2005;142(6):451-66.

38. Blot F, Nitenberg G, Brun-Buisson C. New tools in diagnosing catheterrelated infections. Support Care Cancer 2000;8(4):287-92.

39. Vasudevan C, Oddie SJ, McGuire W. Early removal versus expectant management of central venous catheters in neonates with bloodstream infection. Cochrane Database Syst Rev 2016;4:CD008436.

40. Burnham JP, Rojek RP, Kollef MH. Catheter removal and outcomes of multidrug-resistant central-line-associated bloodstream infection. Medicine (Baltimore) 2018;97(42):e12782.

41. Marschall J, Piccirillo ML, Fraser VJ, Doherty JA, Warren DK. Catheter removal versus retention in the management of catheter-associated enterococcal bloodstream infections. Can J Infect Dis Med Microbiol 2013;24(3):e83-7.

42. Garnacho-Montero J, Diaz-Martin A, Garcia-Cabrera E, Ruiz Perez de Pipaon M, Hernandez-Caballero C, Lepe-Jimenez JA. Impact on hospital mortality of catheter removal and adequate antifungal therapy in Candida spp. bloodstream infections. I Antimicrob Chemother 2013;68(1):206-13.

43. Liu CY, Huang LJ, Wang WS, Chen TL, Yen CC, Yang MH, et al. Candidemia in cancer patients: impact of early removal of non-tunneled central venous catheters on outcome. J Infect 2009;58(2):154-60.

44. Janum S, Afshari A. Central venous catheter (CVC) removal for patients of all ages with candidaemia. Cochrane Database Syst Rev 2016;7:CD011195.

45. Lin SH, Liao WH, Lai CC, Liao CH, Tan CK, Hsueh PR. Association between early and late catheter removal and outcome of elderly patients with catheter-related bloodstream infection and persistent bacteremia caused by methicillin-resistant Staphylococcus aureus. J Am Geriatr Soc 2010;58(6):1197-9.

46. Lee $Y$, Lee $Y T$, Wang $Y C$, Chen $C T$, Sun JR, Liu CP, et al. Risk of mortality of catheter-related bloodstream infections caused by Acinetobacter species: is early removal of the catheters associated with a better survival outcome? J Intensive Care Med 2018;33(6):361-9.

47. Coyle VM, McMullan R, Morris TC, Rooney PJ, Hedderwick S. Catheterrelated bloodstream infection in adult haematology patients: catheter removal practice and outcome. J Hosp Infect 2004;57(4):325-31.

48. Rodriguez D, Park BJ, Almirante B, Cuenca-Estrella M, Planes AM, Mensa $J$, et al. Impact of early central venous catheter removal on outcome in patients with candidaemia. Clin Microbiol Infect 2007;13(8):788-93.

49. Nucci M, Anaissie E, Betts RF, Dupont BF, Wu C, Buell DN, et al. Early removal of central venous catheter in patients with candidemia does not improve outcome: analysis of 842 patients from 2 randomized clinical trials. Clin Infect Dis 2010;51(3):295-303.

50. Nucci M, Braga PR, Nouer SA, Anaissie E. Time of catheter removal in candidemia and mortality. Braz J Infect Dis 2018;22(6):455-61. 